\title{
INTERAÇÕES CRÍTICO-DIALÉTICAS COM AS TECNOLOGIAS NA EDUCAÇÃO
}

\author{
INTERACCIONES CRÍTICO-DIALÉCTICAS CON LAS TECNOLOGÍAS EN LA \\ EDUCACIÓN
}

CRITICAL-DIALECTIC INTERACTIONS WITH TECHNOLOGIES IN EDUCATION

\author{
Adilson Cristiano HABOWSKI ${ }^{1}$ \\ Elaine $\mathrm{CONTE}^{2}$
}

\begin{abstract}
RESUMO: O trabalho aborda os limites das tecnologias na educação, a partir dos discursos extraídos do mapeamento de teses dos Programas de Pós-Graduação em Educação, no intervalo de 2012 a 2016. Trata-se de uma pesquisa hermenêutica realizada por meio da busca de palavras-chave, na Biblioteca Digital Brasileira de Teses e Dissertações (BDTD), tendo por objetivo compreender as contribuições e problemáticas evidenciadas em teses sobre a temática. Os desafios e questionamentos das tecnologias vêm à cena na educação como modelos a serem seguidos, o que fragiliza as experiências de sentido pedagógico na interdependência histórico-formativa e desvela a necessidade de um movimento críticodialético que leve em consideração os conhecimentos construídos na escola. O professor, nesse cenário de mudanças, precisa ser um provocador da reflexão pedagógica roubada pelo desenvolvimento sucessivo de modismos técnicos, como ponto de partida à reconstrução dialética face às tecnologias na educação.
\end{abstract}

PALAVRAS-CHAVE: Pensar crítico-dialético. Tecnologias. Educação. Teses.

RESUMEN: El trabajo aborda los límites de las tecnologías en la educación, a partir de los discursos extraídos del mapeo de tesis de los Programas de Postgrado en Educación, en el intervalo de 2012 a 2016. Se trata de una investigación hermenéutica realizada por medio de la búsqueda de palabras- en la Biblioteca Digital Brasileña de Tesis y Disertaciones (BDTD), teniendo como objetivo comprender las contribuciones y problemáticas evidenciadas en tesis sobre la temática. Los desafíos y cuestionamientos de las tecnologías vienen a la escena en la educación como modelos a seguir, lo que fragiliza las experiencias de sentido pedagógico en la interdependencia histórico-formativa y desvela la necesidad de un movimiento críticodialéctico que tenga en cuenta los conocimientos construidos en la escuela. El profesor, en ese escenario de cambios, necesita ser un provocador de la reflexión pedagógica robada por el desarrollo sucesivo de modismos técnicos, como punto de partida a la reconstrucción dialéctica frente a las tecnologías en la educación.

PALABRAS CLAVE: Pensar crítico-dialéctico. Tecnologías. Educación. Tesis.

\footnotetext{
${ }^{1}$ Universidade La Salle (UNILASALLE), Canoas - RS - Brasil. Pós-graduando em Educação. Bolsista CAPES / PROSUP. Membro do Núcleo de Estudos sobre Tecnologias na Educação - NETE/CNPq. OrcID: http://orcid.org/0000-0002-5378-7981.E-mail: adilsonhabowski@hotmail.com

2 Universidade La Salle (UNILASALLE), Canoas - RS - Brasil. Professora Doutora do Programa de Pósgraduação em Educação. Líder do Núcleo de Estudos sobre Tecnologias na Educação - NETE/CNPq. OrcID: http://orcid.org/0000-0002-0204-0757. E-mail: elaine.conte@unilasalle.edu.br
} 
ABSTRACT: The paper approaches the limits of technologies in education, from the discourses extracted from the mapping of theses of the Graduate Programs in Education, in the interval of 2012 to 2016. It is a hermeneutic research carried out through the search of keywords, in the Brazilian Digital Library of Theses and Dissertations (BDTD), aiming to understand the contributions and problems evidenced in theses on the subject. The challenges and questionings of technologies come to the scene in education as models to be followed, which weakens the experiences of pedagogical sense in the historical-formative interdependence and unveils the need for a critical-dialectical movement that takes into account the knowledge constructed in the school. The teacher, in this scenario of change, needs to be a provocateur of pedagogical reflection stolen by the successive development of technical idioms, as a starting point for the dialectical reconstruction of technologies in education.

KEYWORDS: Critical-dialectical thinking. Technologies. Education. Theses.

\section{Introdução}

Colocar em evidência a questão das tecnologias na educação é algo complexo, pois implica transitar entre o inovador e o tradicional, de modo a articular a cultura digital ao engenho teórico e ao reconhecimento da prática pedagógica, reconstruindo uma relação com os processos vividos nos contextos escolares. O mundo está permeado por revoluções tecnológicas e midiáticas como formas de expressão humana, que vêm à cena social como um saber dos próprios sujeitos, que tanto provoca dependência técnica (fetiche impeditivo de manifestações criadoras) quanto à reflexão sobre a gestão e transmissão do conhecimento, por meio de objetos do mundo digital. A grande questão recai sobre o modo como utilizamos e nos apropriamos das tecnologias na educação, uma vez que são impostas no sistema escolar por modelos de um pensamento computacional em pacotes, o que ignora as experiências pedagógicas e os sentidos comunicativos de potencial humano, reflexivo, de imaginação criadora, reconstrutiva e de emancipação social (HABERMAS, 1987; FREIRE, 1986). A questão se torna ainda mais complexa e paradoxal, já que tais meios não só permitem pensar em formas regradas de políticas de formação de professores, como também repercutem na univocidade de ações humanas mediadas pelas tecnologias sob o rótulo de coerência pedagógica, resultando no despreparo, na massificação e normalização de professores.

Parece que, enquanto o conhecimento expande o horizonte da atividade e do pensamento humanos, a autonomia do homem enquanto indivíduo, a sua capacidade de opor resistência, ao crescente mecanismo de manipulação das massas, o seu poder de imaginação e o seu juízo independente sofrem aparentemente uma redução. $\mathrm{O}$ avanço dos recursos técnicos de informação 
se acompanha de um processo de desumanização (HORKHEIMER, 1976, p. 74).

Há uma desumanização com a cultura instrumental das tecnologias pela redução da cultura do diálogo na educação, das trocas de experiências e conhecimentos, na dificuldade de dar sentido a elas de forma articulada às práticas escolares. Nos espaços formativos acadêmicos são experimentadas tecnologias com apresentações de conteúdos em ambientes digitais virtuais, que sequer conversam com as realidades existentes nas escolas, reproduzindo tecnologias prontas em saberes descolados da vida. Não há nada de errado em mostrar e trabalhar com as inovações tecnológicas nos cursos de formação superior, mas, antes disso, é preciso mostrar que as tecnologias utilizadas dependem dos contextos das escolas para que, a partir daí, possam ser traçados projetos que reconheçam as contradições das realidades educacionais.

\section{Por uma cultura reconstrutiva das tecnologias na educação}

Teoricamente, o conceito de tecnologia envolve múltiplas variáveis, a saber: fatores cognitivos, que dizem respeito aos conhecimentos inerentes a um certo domínio técnico associado a competências e estilos de pensamento; aspectos motivacionais, aspirações e impulsos associados à orientação para realizar a tarefa educativa proposta; fatores de personalidade, capacidade de arriscar e desafiar a si e aos outros como sentido de realização tecnológica; fatores ambientais, que dão condições e apoiam os esforços criativos e técnicos. (ZUIN; ZUIN, 2017; ADORNO, 2005; FEENBERG, 1991). Por conta disso, não basta nos colocarmos ante a essa realidade como espectadores fascinados, precisamos analisar quais os reais efeitos que essas mudanças têm gerado em nossas vidas, especialmente no que tange à dependência tecnológica e às expectativas de emancipação. Pensar a educação como um ato humano e político, por ser um campo da ação social, implica trazer as inovações tecnológicas como integrantes das realidades vigentes. Na verdade, a criação do universo humanizado está permeada por artefatos tecnológicos. Nesse sentido, a educação como possibilidade de transformação de si, do outro e do mundo, precisa estar atenta aos fenômenos subjacentes às tecnologias, para que não caia no relativismo da mera instrumentalização técnica.

Já dizia Freire (1996) que não podemos ser refratários e nem negligenciar as tecnologias, mas fazer uso crítico delas, para apoiar tais processos de mudança e os contextos existenciais, no sentido de mobilizar ações para outros mundos possíveis. 
Nunca fui ingênuo apreciador da tecnologia: não a divinizo, de um lado, nem a diabolizo, de outro. Por isso mesmo sempre estive em paz para lidar com ela. Não tenho dúvida nenhuma do enorme potencial de estímulos e desafios à curiosidade que a tecnologia põe a serviço das crianças e dos adolescentes das classes sociais chamadas favorecidas. Não foi por outra razão que, enquanto secretário de educação da cidade de São Paulo, fiz chegar à rede das escolas municipais o computador. Ninguém melhor do que meus netos e minhas netas para me falar de sua curiosidade instigada pelos computadores com os quais convivem (FREIRE, 1996, p. 97-98).

A construção de uma sociedade mais democrática exige pressupostos educacionais que transcendam a simples objetificação e treinamento humano, no sentido de projetar a mudança social à construção de círculos de cultura (FREIRE, 1996). Com o intuito de garimpar pesquisas e compreender as dinâmicas emergentes no âmbito educacional, visamos discutir os perigos das soluções abreviadas, reducionistas e descomprometidas em relação às tecnologias, bem como as possibilidades de uma prática social transformadora por meio da cultura digital.

O esforço está em dar visibilidade ao conjunto de teses produzidas sobre este tema, contextualizando suas interfaces, limites e articulações com a formação e o ato de educar. A partir do rastreamento de teses produzidas em universidades públicas brasileiras, no portal de domínio público da Biblioteca Digital Brasileira de Teses e Dissertações (BDTD), foram encontradas oitenta (80) teses, no período de 2012 a 2016, utilizando os seguintes descritores: educação e tecnologia. Desse conjunto de 80 teses foram realizados alguns agrupamentos temáticos, de acordo com os títulos evidenciados nos resumos e nas palavras-chave, na tentativa de identificar as vertentes de uma pedagogia crítica frente a tecnificação e a onipresente irrefletida transposição mecânica operada pelo mercado cultural. Contudo, há uma ambiguidade que aflora na tarefa da categorização no campo da educação, mas que é pertinente para que possamos analisar um grande número de teses como se apresenta.

Essas obras foram circunscritas em nove eixos (A; B; C; D; E; F; G; H; I), de acordo com as problemáticas evidenciadas, a saber: A) Processos de ensino e de aprendizagem e as tecnologias na perspectiva interdisciplinar (23 teses); B) Políticas de formação dos Institutos Federais e a docência na educação profissional e tecnológica (11 teses); C) Iniciativas com as novas tecnologias (11 teses); D) Interações dialéticas com os conteúdos tecnológicos (9 teses); E) Análise sobre o projeto PROUCA (Programa um computador por aluno) (7 teses); F) Políticas de formação de docentes e estruturação de cursos na área de educação tecnológica (4 teses); G) Juventudes e tecnologias (4 teses); H) Políticas de implementação de tecnologias digitais (6 teses); I) Discursos de legitimação sobre EaD (5 teses).

As produções englobam diversas projeções e perspectivas sobre o assunto, de modo que das 80 relacionadas, nove (9) foram enquadradas na problemática a ser discutida. 
Circunscritas à temática intitulada "interações dialéticas com os conteúdos tecnológicos", citamos as nove teses referenciadas: 1 tese (UFMG) em 2012, 3 teses (UnB, UFSCar, USP) em 2013, 1 tese (USP) em 2014 e 4 teses (UnB (2), UNESP, USP) em 2015. Salientamos que nas produções da área não encontramos teses de 2016. Diante disso, indagamos: Quais são as preocupações recorrentes nas pesquisas? Que possibilidades e limites as teses da área provocam à articulação das ações pedagógicas e para resistir ao descrédito e à obsolescência das tecnologias na educação?

Para darmos conta desse horizonte investigativo hermenêutico, problematizamos as racionalidades presentes nesse universo educacional mapeado, a partir da realidade do saber tecnológico, para compreendermos e confrontamos as produções teóricas com a cultural contemporânea de procedimentos dialéticos. O trabalho examina cada uma das teses mapeadas, mostrando os principais enfrentamentos, lacunas e considerações feitas, seguindose com uma explanação geral do que foi encontrado em termos de convergências nas teses. As tendências evidenciadas de neutralidade, imediaticidade, unilateralização das tecnologias na educação e os paradoxos dessa problemática, que ao mesmo tempo as colocam em questão, revelam aberturas a outros mundos. Por inúmeros canais, transitamos nesse universo complexo e contraditório das tecnologias na educação, para então chegarmos às considerações finais.

Vale dizer que a problematização das interações dialéticas das tecnologias tem como referencial a Teoria Crítica que nos ajuda a pensar a tecnologia como forma de linguagem, numa dimensão contraditória e criativa da vida humana, esclarecendo suas ambiguidades e seus condicionamentos dirigidos por interesses e pela lógica programada. Em que pese essas considerações, Adorno e Horkheimer (1985), pensadores de visão crítica do mercado lançam em suas análises provocações dirigidas aos processos educativos. Para aprofundar o tema, tecemos interlocuções com a questão da instrumentalidade técnica e da Filosofia da Tecnologia (FEENBERG, 1991) e com os debates em torno das tecnologias em suas interfaces educacionais.

As teses problematizam e questionam a automatização das tecnologias na educação que, muitas vezes, robotizam e adaptam os estudantes e praticamente tornam impotentes os fundamentos interativos porque monopolizam as atividades de ensino. As escolas esquecem que os as tecnologias funcionam de fora para dentro, armazenam e processam informações, mas ainda não são instrumentos de transformação por si, porque dependem das relações dialógicas para o avanço ou retrocesso dos saberes. Tal busca revela-se pertinente à medida que percebemos que poucas são as pesquisas realizadas sobre questões dialéticas que 
emergem das tensões entre os sujeitos e as tecnologias no campo educacional, especialmente em tempos de expansão e democratização das tecnologias em nosso cotidiano (FERREIRA; ROSADO; CARVALHO, 2017). O uso linear, técnico e acrítico das tecnologias pode representar a dependência a informações descontextualizadas, repercutindo em apropriações unívocas e sem sentido do universo tecnológico. Frente às incertezas e diferentes realidades socioeducacionais é preciso pensar sobre as tecnologias para além do aspecto técnico dos afazeres, ampliando a formação por vieses que nos façam dialogar criticamente com os conhecimentos tecnológicos como possibilidades reconstrutivas e aprendentes na educação.

O desafio das tecnologias na educação é evidenciado na relação entre conhecimento e mundo na dimensão humano-social do aprender, para estabelecer a conexão da realidade e assim delinear percursos rumo à democratização das tecnologias. Todo projeto de educação tecnológica passa pelos sentidos que os sujeitos atribuem às tecnologias, pela reconstrução sociocultural que permite metamorfosear saberes, linguagens, contextos, pois as tecnologias digitais estão ancoradas na relação pedagógica do agir com o outro (objetivo, subjetivo e social) e com os limites à formação social, econômica e cultural, o que explica a resistência pedagógica a mera transposição de enfoque sistêmico.

\section{Alicerces metodológicos}

A pesquisa tem seu alicerce na abordagem hermenêutica voltada para a compreensão das contradições presentes nos textos e discursos no campo das tecnologias na educação. $\mathrm{O}$ caminho hermenêutico permite compreender que o conhecimento é fruto de uma tensão constitutiva entre o saber e a ação vivida, que movimenta e transforma ao mesmo tempo os sujeitos históricos, as pesquisas e as mudanças no mundo. A racionalidade educativa é conduzida pelas relações do discurso e da linguagem com o mundo, privilegiando os sujeitos para uma compreensão contextualizada (HABOWSKI; HABOWSKI; CONTE, 2018). O movimento hermenêutico é caracterizado pela busca constante e revisão de contextos sociais para se chegar a uma realidade mais justa e interdependente das ações e planos humanos. $\mathrm{O}$ significado "é incompleto, contraditório e fragmentário e grande parte dele pode estar entregue a cegos demônios. Talvez a leitura seja precisamente nossa tarefa, para que lendo aprendamos a conhecer melhor e a banir os poderes demoníacos" (ADORNO, 2005, p. 7). Nas palavras de Adorno (1966 p. 195), "a dialética negativa deslinda no pensamento o que ele não é", reeditando e atualizando o confronto dialético entre o aparente e a realidade dos modos de comunicação nesses tensionamentos, que desmistificam conceitos e revelam a 
materialidade onde a dialética negativa se instala, ou seja, construída pelos sujeitos com a utilização dos recursos técnicos, materiais e práticas sociais. Theunissen (1983, p.44) afirma que o desvelamento da sociedade pela dialética negativa de Adorno implica "evidenciar o divergente, o dissonante, aquilo que é contrário a uma possibilidade de verdadeira consciência e de autonomia do homem sobre o seu destino [e é], ao mesmo tempo, a possibilidade de contrapor-se ao estabelecido, de negá-lo com a intenção de construir outra situação social".

Sob essa perspectiva, não se trata de realizar uma crítica pessimista ou de descrença do mundo danificado, mas de desenvolver um projeto educativo no qual as perplexidades, polêmicas e adversidades da sociedade tecnologizada possam produzir atos de resistência política, apontando possibilidades para novas formas de pensar e agir do educador, em sintonia com essa aparelhagem digital. A hermenêutica viabiliza a compreensão das contradições e racionalidades presentes nos discursos que tratam das questões críticodialéticas das tecnologias, para identificar os significados comuns, as proposições e as divergências dessas distintas experiências. Nessa perspectiva, tais pesquisas permitem perceber o que está acontecendo no momento e, de fato, trazem uma formação e contextualização relevante para contribuir com os conhecimentos e inquietações da área. Desde o parecer de 1965, podemos observar que as teses de doutorado permitem captar o que está acontecendo na atualidade, em termos de racionalidade de conhecimentos, oferecendo condições para realizar um exercício compreensivo e reflexivo dos horizontes de experiência da temática (ALMEIDA JUNIOR et al., 2005).

\section{Perspectivas mapeadas}

As experiências com as tecnologias na educação exigem quebrar resistências ao novo para abrir-se ao horizonte do pensar, que só faz sentido no diálogo com a tradição cultural. Compreender as tecnologias na educação exige de nós a disposição de aceitar o desconhecido, na própria ameaça contida nos artefatos tecnológicos. Por tais experiências podemos ser transformados todo o dia ou no transcurso do tempo, sempre em busca do olhar (auto)crítico da cultura tecnológica e do princípio pedagógico da (inter)comunicação. Tomadas como indicações de problemas à luz de interesses que se manifestam, as teses que abordam as tecnologias na educação nos levam a descobrir os seus próprios caminhos de reivindicação para ir mais além da lógica das tecnologias como algo dado, ressignificando a realidade na direção da proposição das problemáticas, da reconstrução linguística na concretude da vida. 
Lacerda (2012) em sua pesquisa intitulada "Linguagem e cognição: categorização e significação das concepções de educadores sobre tecnologia digital", propôs buscar através da coleta de entrevistas, as concepções dos próprios educadores sobre quais são os entendimentos de tecnologias digitais. Para Lacerda (2012, p. 18), tal realidade se faz pertinente porque, reconhece que com a chegada dos novos recursos tecnológicos nas instituições de ensino, muitas vezes, faz vários sentimentos, como "empolgação pelas novas perspectivas que se abrem, temor de que os equipamentos substituam os educadores, desconfiança quanto ao potencial das novidades tecnológicas, impotência por não saber utilizar os equipamentos ou incapacidade por conhecer menos do que os alunos sobre as ferramentas digitais". De cunho mais linguístico, Lacerda contribui na tentativa de clarear o conceito de tecnologias digitais no campo educacional, uma vez que estamos submetidos a elas, no entanto, não temos conhecimento de seus potenciais à justificação dos saberes e experiências pedagógicas pela incapacidade (re)criadora. Somente com o contato reflexivo em relação à percepção do papel das tecnologias na organização do mundo atual, no sentido da relação interdependente com a linguagem tecnológica, poderemos chegar com o tempo a uma prática autônoma, recriadora e emancipada das tecnologias digitais na educação. Em suas considerações, Lacerda (2012, p. 182) destaca que “é preciso desfazer o pensamento equivocado de que a tecnologia digital melhora a essência do que se ensina, pois, a tecnologia digital proporciona um processo mais enriquecedor de ensinar e aprender", quando tomado como um certo horizonte preliminar, aberto e acessível que torna possível o (re)conhecimento humano e as suas implicações.

A tese realizada por Silva (2013) e denominada "Letramento digital e pressupostos teórico-pedagógicos: neotecnicismo pedagógico?”, desenvolveu-se na percepção do letramento digital de professores e estudantes como algo que possivelmente está relacionado a pressupostos hegemônicos neotecnicistas. O estudo de Silva (2013, p. 21), "evidencia que a concepção de educação que orienta as práticas de letramento digital de professores e alunos, quando esses fazem uso do computador e da internet no laboratório de informática”, encontrase "subsidiada por pressupostos contra-hegemônicos que possibilitam visões críticas e transformadoras da realidade social". Neste contexto, toda relação de contra-hegemonia é necessariamente uma relação pedagógica e crítica de aprendizagem, um sistema de valores culturais, técnicos e ideológicos, que penetra e se expande, socializa e integra a vida em sociedade.

A problemática baseia-se na preocupação de uma educação como impossibilidade para o letramento digital, ou seja, que não caminha para a emancipação, mas para a alienação 
ideológica do mercado capitalista. Tal hipótese revela toda a ambiguidade inscrita nas tecnologias, uma vez que os professores e estudantes se encontram em situação de vulnerabilidade, pela ausência da criticidade em suas formações. Silva (2013) constata a emergência de processos formativos que visam o posicionamento crítico dos professores, de modo a influenciar também os demais participantes a um olhar crítico e questionador do mundo. A tese constatou que os professores e os estudantes "não possuem consciência e nem clareza teórica de que o desenvolvimento das suas práticas de letramento digital, por meio dos computadores e da internet no laboratório de informática do colégio, estão sendo subsidiadas por pressupostos teóricos e pedagógicos hegemônicos do neotecnicismo", propondo "ao lócus investigado, aperfeiçoamento profissional dos docentes por meio do oferecimento de curso de extensão universitária" (SILVA, 2013, p. 174).

Tudo indica que o instrumental tecnológico tem na educação o caráter de referência (primeiro no sentido informativo) aos profissionais que o usam. De fato, são materiais de que está constituída a atuação do professor (desde o papel, o livro, o quadro negro, o giz, etc.). Se a estrutura do mundo está em significar a totalidade dos instrumentos humanos, então o nexo da linguagem seria como as instruções para usar estes artefatos, pois aprendemos a usar os programas de computador não apenas usando ou vendo os outros usarem, mas através dos discursos vigentes sobre o uso e das nossas próprias reconstruções e reinvenções, de acordo com os contextos e as necessidades que dão sentido às coisas do mundo.

Ao partir de uma realidade latente do contexto escolar, Santos (2013) percebeu a necessidade de um estudo sobre "Indústria cultural, natureza e educação: uma análise do uso de recursos midiáticos sobre a temática ambiental na escola". Assim, com entrevistas e questionários a professores do ensino básico enquanto técnica de coleta de dados, Santos reconheceu a perpetuação de uma consciência (semi)ambiental por parte dos educadores ao fazerem uso que filmes sem um olhar (auto)crítico e compreensivo dos mesmos. Para tal argumento, fundamentou-se nos teóricos críticos da Escola de Frankfurt, principalmente no conceito de semiformação cultural, pois essas concepções "podem ser transmitidas e reforçadas pelos professores quando deixam de intervir nesse processo de reflexão crítica sobre a problemática em questão, consentindo que as ideologias propagadas por esses produtos sejam reforçadas nos educandos" (SANTOS, 2013, p. 12).

No instante em que o educador faz uso de qualquer artefato cinematográfico, sem um olhar crítico subjacente, para abordar questões ambientais, ele não conduz os educandos a uma nova postura, mas a um acirramento da mentalidade de consumo, que é gerada pela semiformação cultural presente nas obras cinematográficas produzidas pela indústria da 
cultura. $\mathrm{O}$ acesso à cultura por meio das tecnologias na educação também não pode caminhar no estreito sentido do ensino profissionalizante para atender ao mercado, com o qual se pretende operar e controlar a racionalidade, mas viabilizar o significado, as implicações políticas e ideológicas desse processo de aprender dialético, de preparação para constituir-se na relação com o mundo. A questão das tecnologias na escola é paradoxal porque muitas escolas estão equipadas com artefatos tecnológicos (TV, computador, lousa digital, etc.), mas os professores que trabalham em sala de aula não sabem usar ou não possuem perspectivas de como podem explorar estas tecnologias para ensinar e aprender. $\mathrm{Na}$ verdade, a formação, muitas vezes, é fornecida apenas aos gestores das escolas que não operacionalizam e não desenvolvem uma apropriação e democratização destes artefatos (depositados em laboratórios, trancafiados e usados apenas com agendamento prévio). Como possível caminho resolutório de tais problemáticas apassivadoras encontradas nas escolas, Santos não propõe a abolição das produções cinematográficas das salas de aula, mas a formação crítica dos educadores, de modo a (des/re)constituírem o que subjaz enquanto semiformação cultural. Os filmes apresentam uma multiplicidade de relações e de referências que nos instigam a olhar, pensar e compreender a realidade educacional, juntamente com as possibilidades de valorização, estimulação e reconhecimento ambiental. Dessa forma, Santos (2013, p. 166) reforça a necessidade uma formação de professores mais críticos e questionadores, promovendo o diálogo e análise das mídias a partir da pedagogia da imagem, fornecendo elementos para habilitá-los para o em sala de aula, pois "a oferta desses recursos e o contato cada vez mais intenso das novas gerações com as mídias e tecnologias é um fato recorrente e inquestionável e aboli-los da escola não significaria garantia alguma de que esses recursos não influenciarão os alunos em suas percepções sobre o que os cerca".

A tese de Matos (2013), intitulada "Dialética da Interação Humano-Computador: tratamento didático do diálogo midiatizado", propõem garimpar a respeito da interação entre tecnologia e ser humano, especialmente em IES (Instituição de Ensino Superior) públicas, uma vez que nestas as tecnologias digitais emergem mais com intuito de mediação do que como possibilidade de Educação a Distância, como ocorre nas instituições privadas. Com base em um estudo de caso, Matos (2013) analisou uma disciplina de pós-graduação strictosensu. Assim, reconheceu a importância e a facilidade proporcionada pelas tecnologias digitais, mas com a necessidade de que a dimensão dialética, de abertura preliminar, de tensão constitutiva, de relação humano-computador, seja possibilitada a partir do interesse e significatividade dos participantes. Para que a interação aconteça, de modo a gerar conhecimento, é preciso uma postura transformadora no sentido da conexão linguística entre 
o mundo, as ações didáticas e as sucessivas revisões e interações dos significados pelos sujeitos, como forma de projetar conhecimentos compartilhados, já que as tecnologias são meios e a interação é reflexo de esforços humanos na circulação da compreensão.

As interfaces tecnológicas dos ambientes virtuais de aprendizagem, apesar de motivadoras, interativas e estimuladoras da criatividade, não garantem por si só que ocorram as interações, tampouco a aprendizagem; nem garantem abordagens educacionais inovadoras. Elas revelaram a oferta de mecanismos para localização de informações e para navegação de forma fácil e produtiva, ou seja, que pudesse implementar o objetivo educacional, a aprendizagem e a construção de conhecimento conforme a proposta pedagógica (MATOS, 2013, p. 193).

Contudo, o pesquisador encerra sua análise reforçando uma constante (re)avaliação da interação humano-computador e de softwares educacionais, recomendando "a necessidade de maior diálogo interdisciplinar entre educação e Ciência da Computação, de modo que as soluções tecnológicas para a educação estejam cada vez mais conectadas com a realidade e as necessidades educacionais" (MATOS, 2013, p. 193).

De caráter fenomenológico-hermenêutico, Nakashima (2014) escreveu a tese sobre "A dialética dos conhecimentos pedagógicos dos conteúdos tecnológicos e suas contribuições para ação docente e para o processo de aprendizagem apoiados por ambiente virtual". A pesquisadora parte do entendimento de que são os estudantes que fazem suas próprias descobertas, de modo que a tecnologia se revela um grande meio nesse percurso. Não é mais possível sustentar uma educação em que o estudante é um ser passivo, mas ativo, que (re)constrói seu próprio conhecimento. Todavia, é necessário "um processo de ação-reflexãoação", que não só gere conhecimento, mas a emancipação do próprio estudante pela possibilidade da construção de uma rede discursiva e cooperativa de interpretação (NAKASHIMA, 2014, p. 31). Ao fazer uso de uma gama de autores, Nakashima encontra o fio condutor na necessidade de mudanças da escola, bem como da pedagogia, proporcionando novos espaços e meios para a construção do conhecimento. Nakashima (2014, p. 48) entende que o papel do professor, enquanto mediador do processo de ensino e aprendizagem, requer estratégias diferenciadas, ancoradas "por tecnologias selecionadas a partir de critérios que identifiquem os recursos que transformem a sala de aula em espaço de aprendizagem ativa e de reflexão coletiva, que contribuam para a produção e utilização das informações para o posicionamento crítico diante da realidade".

Toda relação pedagógica é possível em virtude da abertura ao mundo ante as possibilidades de aprendizagens ofertadas pelas tecnologias, mas que só é garantida quando ressignificada nas práticas. É necessário que o estudante seja autor de suas próprias 
descobertas, e o educador, um guia sensível às diferentes formas de expressão no percurso que o estudante projeta. Por isso, "foi compreendido que a tecnologia é apenas suporte, apoio, auxílio e não um fim em si mesma; não pode ser o foco principal para a realização de tarefas e planejamento de situações-problema”, mas possibilidade do estudante ser protagonista na construção do próprio conhecimento, à luz da orientação do professor (NAKASHIMA, 2014, p. 225).

Em busca de uma educação emancipadora por meio do uso das Tecnologias, Carvalho (2015) intitulou sua tese de "Educação cidadã a distância: uma perspectiva emancipatória a partir de Paulo Freire". Assim, é notória a necessidade e a dificuldade de transformar a Educação a Distância $(\mathrm{EaD})$ em uma possibilidade de emancipação e de formação cidadã dos sujeitos, uma vez que esta tende a cair no tecnicismo educacional, sem levar a uma abertura ao mundo e a construção de uma disposição (auto)crítica. Por isso, "este trabalho pretende contribuir com uma Educação de caráter emancipatório, com sujeitos críticos e comprometidos com a melhoria de vida de todos e do planeta, por meio de uma discussão sobre formação cidadã pela modalidade a distância" (CARVALHO, 2015, p. 13). Mas, antes de caminhar para a formação cidadã por meio da EaD, Carvalho (2015, p. 21) destaca que "não pode haver Educação onde há distância. Educação exige presencialidade: o sujeito mobilizando sentidos, valores, conhecimentos prévios para dialogar com o objeto em estudo e/ou com outros sujeitos, independente do tempo e de estarem no mesmo local". Portanto, a mudança começa na postura em relação aos esforços para o restabelecimento do diálogo humano, pois mesmo sendo mediada pelas tecnologias, ela não pode ser uma educação que distancie os sujeitos, mas que os aproxime como cidadãos do mundo atual ou virtual.

Embora na tradição pedagógica o educador seja apresentado tendenciosamente na EaD como mediador dos processos de ensino e de aprendizagem, Carvalho adverte sobre a ineficácia de um mediador na construção de um sujeito emancipado, cidadão e crítico, sendo necessário ainda a promoção da relação entre estudante e tecnologia, tendo o professor a função social de ser um provocador e não simplesmente um mediador. "O educador a distância não é mediador, portanto, mas um provocador dessas tensões, redescobrindo junto com o estudante o objeto na sua relação com o mundo, com vistas a transformá-lo. Para isso, ambos devem poder contar com materiais de estudo coerentes com esse desvelamento" (CARVALHO, 2015, p. 194).

Já a tese de Araújo (2015), intitulada “Advento da Emancipação Humana pelo Estatuto das Redes Ciberculturais da Aprendizagem Colaborativa”, propõem olhar as redes ciberculturais como meios emancipatórios no campo educacional, rompendo com a corrente 
alienante oriunda de estruturas tecnicistas. A partir de um estudo de caso e utilizando como técnica de coleta de dados entrevistas percebeu-se a significativa presença da cibercultura na vida cotidiana, que põem a claro a necessidade no campo educacional da ideia de mundo como totalidade de instrumentos. Araújo (2015, p. 23), entende que há "a necessidade de se refletir sobre uma pedagogia que não se seduza pelo fetiche da técnica e pelas maravilhas que a publicidade pode criar". No entanto, não se faz uma "negação dos valores tecnológicos, pelo contrário, defende-se o seu uso e a experiência tecnológica em todos os níveis. Por outro lado, de modo consciente e com papeis bem claros - a máquina opera para atender as necessidades da humanidade e, não o contrário, escravos da técnica" (ARAÚJO, 2015, p. 23),

Esta pertença ao mundo tecnológico não significa apenas um limite adaptativo, mas exige se apropriar de uma pedagogia que desmistifique e encaminhe para um olhar crítico, que projeta nas tecnologias digitais a base de suas possibilidades de renovação, com potenciais transformadores para a emancipação dos sujeitos (e não a nulidade e o reducionismo técnico frente a perplexidade tecnológica que gera medo, ameaça à autoridade pedagógica e desinteresse). É preciso desenvolver possibilidades de abertura ao mundo e não a adaptação das tecnologias digitais no meio educativo, pois a sociedade contemporânea está permeada por redes ciberculturais e necessita de uma formação crítica e dialógica para utilizálas de modo independente e metamorfoseante do próprio saber, assegurando o aprender com o outro. Portanto, conforme Araújo (2015, p. 224), “o perfil emancipatório das redes cibernéticas parece algo factível", mas ainda precisa ser muito "trabalhado, porque a tecnologia permite que haja práticas colaborativas de aprendizagem, mas não assegura tal prática. Isso depende em grade parte da consciência crítica necessária à promoção de indivíduos autônomos".

Barcelos (2015), em sua tese desenvolvida a partir de um estágio, denominada de "Imagem-aprendizagem: experiências da narrativa imagética na educação" procurou retratar esta questão a partir de três dimensões: narrativo-reflexivo, simbólico-estético e linguagem audiovisual, ambas amparadas na leitura crítica de Walter Benjamin. Nesta tese são levantadas questões buscando o crescimento e a valorização de uma aprendizagem que rompa com os padrões de senso comum e parta para a realidade a qual os estudantes estão inseridos, já que tal realidade é permeada por imagens. Nas palavras de Barcelos (2015, p. 19), as reflexões da pesquisa "são o fruto de uma caminhada com o cinema e com a linguagem audiovisual que remonta às minhas primeiras experiências docentes e perfaz um labirinto de descobertas onde a imagem se configura como forma de conhecimento e emancipação". 
A pesquisadora parte da imagem-aprendizagem para a construção do saber, conectando tal conhecimento com a tradição socio-histórica presente nas experiências dos educandos. $\mathrm{Na}$ medida em que estes vão se identificando e entrando em jogo com tais imagens, o conhecimento começa a fazer mais sentido e ampliar-se na vida dos estudantes, rompendo com a lógica fragmentária que muitas vezes paira sobre a educação. Toda a possibilidade acende a uma análise narrativo-reflexiva, que visa debater sobre as obras imagéticas humanas. Porém, “em tempos de aceleração, esta é uma prática que exige tempo de docentes e educandos, aprender a olhar criticamente e também a falar sobre a experiência não é uma tarefa fácil, exige paciência, concentração e uma dedicação que ultrapassa muito os limites da fruição que o cinema oferece" (BARCELOS, 2015, p. 122). Justamente, com o olhar crítico se vai muito além do conformismo das obras arrancadas dos seus contextos e capturadas de modo imediato, encontrando um sentido mais profundo e original em cada produção, que vem agregar na construção de diferentes sentidos e conhecimentos manifestados na autenticidade de cada educando. Reconhecer uma obra de arte nas suas minúcias, permitindo-se adentrar em seu sentido mais original, não é meramente tornar-se um apreciador de arte, mas um descobridor de mundos na vida das necessidades correntes, pois tal ato possibilita integrar tal capacidade nos afazeres mais triviais da vida. Isto equivale afirmar que a imagem-aprendizagem "existe como um potencial a ser explorado, criado e recriado e, como em final de filme aberto, a sequência desta narrativa segue pelas salas aulas, no visionamento, nas experiências com a linguagem audiovisual, nas possibilidades que a visualidade oferece à educação" (BARCELOS, 2015, p. 128). Trata-se da própria situação em que nos encontramos e nos constituímos como seres em obra.

Já a tese de Geraldi (2015) apresenta "Uma análise das manifestações docentes sobre o uso das tecnologias da informação e comunicação nas escolas públicas de nível médio da cidade de Taquaritinga - SP”. Dando seguimento a esta reflexão, parte de um estudo de caso acerca das realidades educacionais públicas e passa a analisar a existência de muitos professores resistentes à adesão e à utilização das TIC em contexto escolar. Geraldi (2015, p. 21) defende que "a inserção de TIC na educação proporcionou a criação de novos paradigmas na construção do saber e na constituição do processo ensino-aprendizagem na escola". Mas denuncia que ainda vivemos em tempos obscuros no entendimento das relações didáticopedagógicas proporcionadas pelas TIC, reconhecendo nelas uma contradição formadora. Se o uso das TIC nas escolas é algo identificado nos ambientes educacionais e na sociedade como um todo, também é urgente a necessidade de aprimorar e atualizar o uso destas tecnologias, além de fornecer uma adequada infraestrutura física, propiciando um espaço de possibilidades 
ao ensinar e ao aprender. A tecnificação do mundo e das relações humanas traz defasagens correlatas à falta de formação dos docentes e a utilização instrumental e operacional das TIC, principalmente em contextos educacionais públicos. Segundo Geraldi (2015, p. 117-118), “pelas manifestações dos professores, percebeu-se que muitos deles ainda preferem usar o método tradicional de ensino, em que o professor é o detentor do conhecimento e o aluno é o ouvinte dessa prática”.

Ante a tal resistência e negação do pensar por meio das TIC perpetua-se uma estrutura linear, formal e abstrata de interação educativa, já que o estudante não pode ser coparticipante na sua formação, mas um mero ouvinte manipulado pelas opiniões correntes, sem condições de problematizá-las nos espaços formativos. Para Geraldi (2015, p. 121), “o professor é o mediador do processo ensino-aprendizagem e seu envolvimento é parte decisiva para o sucesso efetivo da inserção de novas ferramentas da aprendizagem nesse ambiente”. Portanto, precisamos caminhar para uma formação da docência que rompa com tal negligência, que emana de um certo medo de aventurar-se no mundo das TIC, propiciando espaços de indagação, compreensão, aprendizagens horizontais, dialógicos e colaborativas.

\section{A experiência crítico-dialética: uma postura necessária?}

Os pensadores da Escola de Frankfurt apresentam uma visão dialética dos artefatos tecnológicos, compreendendo-os como produtos culturais que refletem o desenvolvimento capitalista e as consequências da eficiência e da produtividade no âmbito da formação cultural e da educação. Assim, Adorno e Horkheimer têm contribuído para os debates sobre a questão da instrumentalidade técnica e sua relação com o capital, que por sua vez, foi responsável pela mercadorização da cultura e pela tendência à tecnificação da vida. Adorno e Horkheimer (1985) esclarecem sobre a forma como as produções culturais vão gradativamente se colocando conforme a lógica do fetiche da mercadoria, de modo que o desejo de consumo se sobressai ao valor da vida cotidiana. Em sua lógica de mercado, caracterizada pelo consumo exacerbado, pela cultura do descarte e da produção de novas necessidades promove uma postura acrítica e massificada frente ao mundo, destruindo os vínculos com a alteridade.

Adorno aprimora a questão da dialética negativa, que se refere à crítica a positividade sintética presente na dialética inaugurada por Platão e Hegel, tendo em vista a impossibilidade de síntese, somada ao fato de que a realidade não se identifica com o conceito e que por isso é negativa. A partir daí, manifestou em seus escritos a necessidade de uma educação que seja autocrítica e emancipadora, como uma das formas para que a barbárie humana não se repita, 
anunciando a reeducação como o último reduto possível frente ao império da semiformação socializada pela indústria cultural. A dialética negativa na sociedade tecnológica propõe que nos tornemos (auto)críticos ou estaremos fadados a uma vida de passividade, de acúmulo massificado de sensações e impressões cada vez mais intensas, sem que com isso haja tempo para as reflexões e experiências formativas. A subjetividade parece negligenciada e reduzida a acontecimentos desarmônicos e passageiros de uma experiência desmoralizada de educação.

Türcke (2010), a partir da ideia de contrafogo de Pierre Bourdieu, afirma que o choque imagético difundido pelas produções da indústria cultural precisa ser transformado, em termos benjaminianos, a partir de um choque reflexivo ou ainda de imagens-pensamento. Ou seja, um processo de pensar sobre as imagens que são diariamente consumidas por professores e estudantes, com o objetivo de que as ideias estereotipadas sejam transformadas em formação e reflexão crítica da realidade (HABOWSKI; CONTE, 2018). Entretanto, esse tipo de exercício que tem sido sabotado pela tempestade de estímulos audiovisuais disseminados pelas tecnologias digitais e midiáticas. Ao se acomodar em fantasias virtuais, os estudantes perdem a capacidade de assimilação das experiências concretas e de desenvolvimento do pensar crítico sobre o cotidiano, pois não conseguem dialogar com as necessidades e conjunturas do próprio contexto em que vivem.

Atualmente, a atrofia da imaginação e da espontaneidade do consumidor cultural não precisa ser reduzida a mecanismos psicológicos. Os próprios produtos - e entre eles em primeiro lugar o mais característico, o filme sonoro - paralisam essas capacidades em virtude de sua própria constituição objetiva. São feitos de tal forma que sua apreensão adequada exige, é verdade, presteza, dom de observação, conhecimentos específicos, mas também de tal sorte que proíbem a atividade intelectual do espectador se ele não quiser perder os fatos que desfilam velozmente diante de seus olhos (ADORNO; HORKHEIMER, 1985, p. 104).

Com a incessante circulação de informações e manipulação de significações, a relação comunicativa torna-se perturbada, pois é a dialética da intercomunicação que coloca em questão as intencionalidades discursivas, transformando os sentidos e os contextos. Em empregos automatizados são as próprias máquinas que distribuem as informações recorrentes. Por isso, as discussões sobre o uso dos artefatos tecnológicos têm gerado debates ambíguos: de um lado, a tecnologia é apresentada como fantástica ferramenta para ampliação da atividade democrática das massas e da inteligência coletiva, considerada ainda como potencial para uma revolução cibercultural, como afirma Lévy (2000). Sob outro viés, o aparato tecnológico é compreendido dentro de um contexto com base em interesses capitalistas e modismos ideológicos, sustentado pelos teóricos críticos. Contudo, a indústria cultural numa 
sociedade globalizada, além de desvirtuar a capacidade de pensar influencia ideologicamente na despersonalização e formação estética dos sujeitos.

Quanto mais opaca e complicada se torna a vida moderna, tanto maior o número de pessoas tentadas a agarrar-se desesperadamente a clichês que parecem impor alguma ordem ao que, de outro modo, é incompreensível. Assim, as pessoas não somente perdem a verdadeira visão interior da realidade, mas também acabam perdendo a própria capacidade de experimentar a vida, embotada pelo uso constante de óculos azuis e cor de rosa (ADORNO, 1978, p. 557).

Diante disso, precisamos indagar sobre os rumos e os sentidos que atribuímos aos meios tecnológicos para a efetivação da capacidade de diálogo intersubjetivo. Adorno (2003, p. 141-142) ressalta que o escopo da educação é "a produção de uma consciência verdadeira. Isto é: uma democracia com o dever de não apenas funcionar, mas operar conforme seu conceito, demanda pessoas emancipadas. Uma democracia efetiva só pode ser imaginada enquanto uma sociedade de quem é emancipado". Ainda, para Adorno (2003), a educação implica emancipação e não se reduz à perspectiva de conformidade ao mundo existente. $\mathrm{Na}$ verdade, revela que a ambiguidade da educação reside simultaneamente na adequação ao instituído e na articulação com a formação e o ato de educar emancipatório. O pensamento dialético da contradição é apontado como o suporte para superar a semiformação socializada e a dissolução da cultura. Na perspectiva de Adorno (1996, p. 388), "a formação cultural agora se converte em uma semiformação socializada, na onipresença do espírito alienado, que, segundo sua gênese e seu sentido, não antecede à formação cultural, mas a sucede".

Com base nos dados coletados, percebemos inúmeras investidas a respeito de um processo mais emancipador quanto ao uso dessas tecnologias em sala de aula, especialmente na relação dialética humano-computador e no papel do professor nesse processo. Assim, garimpando as teses produzidas, encontramos caminhos para a compreensão dos problemas contemporâneos na educação e para atender as demandas formativas à democratização do acesso ao conhecimento, (re)construção e interpretação das linguagens tecnológicas e suas consequências de caráter social e não-linear.

A rigor, não é possível negar a presença das tecnologias em nossas realidades educacionais, elas são parte constitutiva e dinâmica do processo de construção do conhecimento na contemporaneidade (CONTE; HABOWSKI; RIOS, 2019). Nas pesquisas levantadas, foi possível perceber o quão frutíferas são tais interações, confrontando o educando e o próprio educador a um novo mundo, a novas possibilidades, que podem surgir de decisões arbitrárias e expropriantes da temporalidade e dos contextos humanos. Mas, não 
destoando de tal avanço, é preciso uma revisão dos meios tecnológicos e da noção de mundo (limítrofe), uma vez que estão permeados de ideologias e, ao invés de nos possibilitarem uma formação humanizada e emancipada, podem nos conduzir a uma lógica alienante. Freire (1992, p. 133) encontra o ponto de referência para articular uma abertura às ações tecnológicas no desenvolvimento do pensamento pedagógico, ao afirmar, "o que me parece fundamental para nós, hoje, mecânicos ou físicos, pedagogos ou pedreiros, marceneiros ou biólogos é a assunção de uma posição crítica, vigilante, indagadora, em face da tecnologia".

Especialmente ao que tange às questões dialéticas na relação humano-computador, por meio das pesquisas encontradas na BDTD, revela-se a necessidade de não permanecer no reducionismo das tecnologias digitais pela pedagogização despreparada e improvisada destes artefatos, mediante a revisão e a responsabilização tecnológica nas proposições educacionais. Mesmo algumas pesquisas trazendo distintos enfoques e experiências dentro da temática, vemos que ambas delimitam e articulam reflexões em torno da emancipação dos participantes na relação humano-computador, visto que são formas eminentes da experiência formativa, criativa e humana da própria realidade. Algumas discorrendo, nesse meio, sobre o professor como um mediador (NAKASHIMA, 2014), outras como um provocador (CARVALHO, 2015), já que um simples mediador não tem força de recriação e auxílio no questionamento dos saberes e no desenvolvimento de uma postura (auto)crítica, reflexiva e sensível.

A formação dos professores ressoa na capacidade de interpretar e reinventar as tecnologias digitais, sem esgotá-las nos usos em si, que não provoca o pensar em relação com a tecnologia, mas gera tecnicismos e dependência técnica. Tal formação não requer meramente o ensino arbitrário do manuseio técnico dos aparatos tecnológicos educacionais, mas a superação que começa com o diálogo sobre esses artefatos (HABOWSKI; CONTE, 2017). Ao refletir sobre a instrumentalidade e os limites das tecnologias na educação, somos levados a reconhecer as possibilidades que elas trazem a abertura histórica e linguística de diferentes mundos. Assim, a motivação tecnológica é válida na educação enquanto é reconhecida pelos sujeitos (gestores, professores e estudantes). Se as tecnologias digitais abrem e fundam um mundo, elas não podem reduzir-se a um simples instrumento educacional novo, mas precisam penetrar o mundo pedagógico e entrar em diálogo com a nossa perspectiva de mundo, que nos obriga a modificá-la e aprofundá-la.

A compreensão crítica da tecnologia, da qual a educação de que precisamos deve estar infundida, e a que vê nela uma intervenção crescentemente sofisticada no mundo a ser necessariamente submetida ao crivo político e ético. Quanto maior vem sendo a importância da tecnologia hoje tanto mais se afirma a necessidade de rigorosa vigilância ética sobre ela. De uma ética a 
serviço das gentes, de sua vocação ontológica, a do ser mais e não de uma ética estreita e malvada, como a do lucro, a do mercado. (FREIRE, 2000, p. 101-102).

Aos questionamentos e problemas levantados na pesquisa das teses coletadas, sobressaiu a preocupação de que não é pela exclusão ou negação das tecnologias do debate nas escolas que estamos libertos de sermos moldados e influenciados pelas ideologias alienantes de mercado da manipulação técnica das tecnologias. Mas, pelo contrário, já que as tecnologias são criações humanas e estão presentes no todo de nossas vidas. É necessário reconstruir o sentido das tecnologias na educação, para pensá-las criticamente rumo a uma formação emancipada dos sujeitos frente à cultura digital. Por isso, enquanto possibilidade de trilhar tal caminho, encontramos na práxis tecnológica uma expressão para superar a rejeição e a crise do pensar tecnológico na educação.

Tal práxis, nada mais é do que um processo crítico-reflexivo que visa humanizar as relações tecnológicas, possibilitando assim, que as interações dialéticas humano-computador, sejam exigências de um exercício crítico e emancipador da práxis social. Parte-se da contextualização da tecnologia, bem como da compreensão e utilização, de modo a desenvolver, através de tal práxis, uma gama de conhecimentos que nos possibilitam resistir ao fetichismo (função conservadora e desresponsabilizada da cultura) produzido pela tecnologia. Cabe ainda debater sobre as conjecturas político-educacionais do quanto a educação é impactada pela expansão, acesso e sucateamento das tecnologias no contexto escolar. As possibilidades são inúmeras, tanto para uma formação alienada quanto emancipada, a diferença consiste na provocação manifestada pelo professor ao educando no instante que ele interage com as tecnologias.

A introdução das tecnologias na educação e nos cursos de formação de professores tem esbarrado em contingências e problemáticas comuns aos sistemas de ensino, como por exemplo, a ausência de políticas formativas inovadoras, muitas vezes, é desarticulada das necessidades, descontínuas e sem perspectivas cooperativas para refletir sobre as práticas culturais desenvolvidas. A estrutura escolar também restringe o acesso às tecnologias (trancafiadas em laboratórios) e inviabiliza momentos de diálogo coletivo entre os profissionais, quando despreza a historicidade da práxis construída nos contextos e exige dos professores uma atuação com autonomia (solitária e destituída de interdependência) para reconstruir conhecimentos inovadores (de um diálogo inexistente em uma sociedade global diria Freire), perpetuando a simples adoção de comportamentos e instrumentos de assimilação equivocada e fragmentária (PUGENS; HABOWSKI; CONTE, 2018). 


\section{Considerações finais}

As teses nos revelam as preocupações mais imediatas e de aproximação com o campo empírico-analítico, em termos de déficit dialógico, cognitivo e de compreensão, que demonstram ações ainda superficiais à resolução de problemas nos debates acadêmicos sobre educação e tecnologia. Assim, as teses coletadas permitiram olhar criticamente a tecnologia educativa e o que há de convergência nesses contextos, para discutir sobre as potencialidades, os limites e as ações das tecnologias digitais, a partir da questão das interações dialéticas com os conteúdos tecnológicos que, rotineiramente, são inviabilizados como possibilidade para o desenvolvimento de uma pedagogia das tecnologias digitais pela estruturada imposição de discursos normativos saturados. Além disso, as pesquisas recentes puderam viabilizar novos sentidos e implicações teórico-práticos à socialização e ao entendimento dos conhecimentos para a sociedade em geral, fortalecendo o potencial comunicativo, reflexivo e a crítica do nosso tempo.

Nesta pesquisa, diversas questões e problemáticas emergiram, mas, assevera-se uma preocupação maior no aprimoramento da humanização, especialmente no contexto escolar, que traz os ranços de algumas políticas reguladoras da própria experiência com as tecnologias. As teses giraram em torno de uma pluralidade de reflexões críticas com dimensões linguísticas, históricas, dialéticas e até mesmo biológico-ambientais da formação dos sujeitos. Em ambas as teses, os recortes feitos consideraram as forças sociais, econômicas, políticas, as modificações e instabilidades da presença tecnológica na vida cotidiana, bem como a necessidade de integração e contextualização dos artefatos tecnológicos na escola, gerando uma postura (re)construtiva do próprio conhecimento, rompendo com a lógica educacional reificada. O princípio dialético que percebe a realidade educacional, a partir de uma visão dialógica de elementos pedagógicos antagônicos e em constante movimento gera o (re)conhecimento da diversidade e discrepância entre o projeto educativo e seus resultados, cuja complexidade de questões lançadas sobre o próprio advento tecnológico abre novas redes de sociabilidade à construção do próprio conhecimento e do pertencimento ao fenômeno investigado.

Aparentemente, se não houver uma interação provocativa por parte do professor na relação educando e tecnologias, o fetichismo presente nas tecnologias conduzirá os circuitos de comunicação a assimetrias classificatórias, deterministas, alienantes e conservadoras de instrumentalidades acríticas. Por isso, através de uma práxis tecnológica é possível um processo constante de desmitificação desses artefatos, já que tal caminho desafia o professor a 
sair da zona de conforto e ser uma figura ativa nas interações dos sujeitos com os conteúdos e os meios tecnológicos. Em outras palavras, o (re)conhecimento destas teses produzidas se mostra essencial para refletir sobre a interdependência das práticas de formação com as necessidades e defasagens das ações escolares, visto que a tecnologia separada do mundo da vida pode produzir desvios. Para dar conta da totalidade, torna-se necessário o fortalecimento do diálogo das teorias com as diferentes práxis no desenvolvimento dos processos de aprender e educar no campo das tecnologias, refletindo criticamente sobre os déficits das tecnologias no campo da educação. Para ultrapassar a operacionalidade técnico-normativa inscrita na educação é necessário expandir os horizontes reflexivos com base no pensar (auto)crítico da vida em sociedade, buscando elucidar as contradições formativas da linguagem tecnológica como forma de desenvolver a capacitação para o agir social e abertura da própria experiência educativa.

\section{AGRADECIMENTOS: CNPq e FAPERGS}

\section{REFERÊNCIAS}

ADORNO, T. W. O fetichismo na música e a regressão da audição. São Paulo: Nova Cultura, 1966. (Col. Os Pensadores).

ADORNO, T. W. A televisão e os padrões da cultura de massa. In: ROSEMBERG, B.; WHITE, D. M. (org.). Cultura de Massa: as artes populares nos Estados Unidos. São Paulo: Cultrix, p. 546-562, 1978.

ADORNO, T. W. Educação e emancipação. 3. ed. Rio de Janeiro: Paz e Terra, 2003.

ADORNO, T. W. Indústria cultural e sociedade. Trad. Julia Elisabeth Levy. São Paulo: Paz e Terra, 2005.

ADORNO, T. W; HORKHEIMER, M. A dialética do esclarecimento. Rio de Janeiro: Jorge Zahar, 1985.

ALMEIDA J. et al. Parecer CFE n. 977/65, aprovado em 3 dez. 1965. Revista Brasileira de Educação, Rio de Janeiro, n. 30, p. 162- 173, 2005.

ARAÚJO, R. H. P. Advento da emancipação humana pelo estatuto das redes ciberculturais de aprendizagem colaborativa. 2015. 263 f. Tese (Doutorado em Educação) - Universidade de Brasília, Brasília, 2015.

BARCELOS, P. Imagem-aprendizagem: experiências da narrativa imagética na educação. 2015. 203 f. Tese (Doutorado em Educação) - Universidade de Brasília, Brasília, 2015. 
CARVALHO, J. S. Educação cidadã a distância: uma perspectiva emancipatória a partir de Paulo Freire. 2015. 211 f. Tese (Doutorado em Educação) - Universidade de São Paulo, São Paulo, 2015.

CONTE, E.; HABOWSKI, A. C.; RIOS, M. B. Ressonâncias das tecnologias digitais na educação. Revista Ibero-Americana de Estudos em Educação, Araraquara, v. 14, p. 31-45, jan./mar., 2019. DOI: 10.21723/riaee.v14i1.11110

FEENBERG, A. Critical theory of technology. New York: Oxford University Press, 1991.

FERREIRA, G. M. S; ROSADO, L. A. S.; CARVALHO, J. S. (Org). Educação e tecnologia: abordagens críticas. Rio de Janeiro: SESES, 2017.

FREIRE, P. Pedagogia da esperança: um reencontro com a pedagogia do oprimido. Rio de Janeiro: Paz e Terra, 1992.

FREIRE, P. Pedagogia da autonomia: saberes necessários à prática educativa. 6.ed. São Paulo: Paz e Terra, 1996.

FREIRE, P. Pedagogia da Indignação: cartas pedagógicas e outros escritos. São Paulo: UNESP, 2000.

GERALDI, L. M. A. Uma análise das manifestações docentes sobre o uso das tecnologias da informação e comunicação nas escolas públicas de nível médio da cidade de Taquaritinga - SP. 2015. 121 f. Tese (Doutorado em Educação) - Universidade Estadual Paulista Júlio de Mesquita Filho, Araraquara, 2015.

HABERMAS, J. Dialética e Hermenêutica. Trad. Álvaro Luiz Montenegro Valls. Porto Alegre: L\&PM, 1987.

HABOWSKI, A. C.; CONTE, E. Outros olhares sobre as tecnologias na educação. Anais[...] Salão UFRGS 2017: SIC - XXIX SALÃO DE INICIAÇÃO CIENTÍFICA DA UFRGS. 2017. Disponível em:

https://www.lume.ufrgs.br/bitstream/handle/10183/175553/Resumo_52228.pdf?seq. Acesso em: 20 dez. 2018.

HABOWSKI, A. C.; CONTE, E. O poder das imagens e símbolos - repercussões sóciohistóricas. Revista Teias, Rio de Janeiro, v. 19, n. 55, out./dez. 2018. DOI 10.12957/teias.2018.34081

HABOWSKI, A. C.; JACOBI, D. F.; CONTE, E. Garimpando ideias para a reconstrução do círculo hermenêutico e do círculo de cultura. Revista Teias, Rio de Janeiro, v. 19, n. 53, abr./jun. 2018. DOI 10.12957/teias.2018.29719

HORKHEIMER, M. Eclipse da razão. Trad. Sebastião Uchoa Leite. Rio de Janeiro: Editorial Labor do Brasil, 1976.

LACERDA, N. A. Linguagem e cognição: categorização e significado das concepções de educadores sobre tecnologia digital. 2012. $201 \mathrm{f}$. Tese (Doutorado em Educação) Universidade Federal de Minas Gerais, Minas Gerais, 2012. 
LÉVY, P. A inteligência coletiva. Por uma antropologia do ciberespaço. 3. ed. Tradução de Luiz Paulo Rouanet. São Paulo: Edições Loyola, 2000.

MATOS, E. S. Dialética da interação humano-computador: tratamento didático do diálogo midiatizado. 2013. 269 f. Tese (Doutorado em Educação) - Universidade de São Paulo, São Paulo, 2013.

PUGENS, N. B. HABOWSKI, A. C.; CONTE, E. Os processos de ensino atravessados pelas tecnologias digitais. EmRede - Revista de Educação a Distância, Porto Alegre, v.5, n.3, ago./dez, 496-509, 2018. Disponível em:

https://www.aunirede.org.br/revista/index.php/emrede/article/view/371/396. Acesso em: 20 dez. 2018.

NAKASHIMA, R. H. R. A dialética dos conhecimentos pedagógicos dos conteúdos tecnológicos e suas contribuições para a ação docente e para o processo de aprendizagem apoiados por ambiente virtual. 2014. 287 f. Tese (Doutorado em Educação) - Universidade de São Paulo, São Paulo, 2014.

SANTOS, J. R. Indústria cultural, natureza e educação: uma análise do uso de recursos midiáticos sobre a temática ambiental na escola. 2013. 198 f. Tese (Doutorado em Educação) - Universidade Federal de São Carlos, São Paulo, 2013.

SILVA, E. M. Letramento digital e pressupostos teórico-pedagógicos: neotecnicismo pedagógico? 2013. 197 f. Tese (Doutorado em Educação) - Universidade de Brasília, Brasília, 2013.

THEUNISSEN, M. Negativität bei Adorno. In: FRIEDEBURG, L.; HABERMAS, J. (Hrsg.). Adorno-Konferenz. Frankfurt/Main: Suhrkamp, 1983.

TÜRCKE, C. Sociedade excitada: filosofia da sensação. Campinas: Editora da Unicamp, 2010.

ZUIN, A. Á. S.; ZUIN, V. G. Lembrar para elaborar: reflexões sobre a alfabetização crítica da mídia digital. Pro-Posições, Campinas, v. 28, n. 1, p. 213-234, abr. 2017.

\section{Como citar este artigo:}

HABOWSKI, Adilson Cristiano; CONTE, Elaine. Interações crítico-dialéticas com as tecnologias na educação. Revista Ibero-Americana de Estudos em Educação, Araraquara, v. 15 , n. 1 , p. 266-288, jan./mar. 2020. E-ISSN: 1982-5587. DOI: https://doi.org/10.21723/riaee.v14i4.11993

Data da Submissão: $16 / 12 / 2018$

Revisões Requeridas: 20/04/2019

Aceite em: 26/09/2019

Publicado em: 02/01/2020 